\title{
The Percent-Change Extension to the DuPont Identity
}

\author{
David Eagle \\ Dept. of Management, Eastern Washington University \\ 668 N. Riverpoint Blvd., Spokane, WA 99202-1677, USA \\ Tel: 1-509-828-1229Ｅ-mail: deagle@ewu.edu
}

Arsen Djatej (Corresponding author)

Dept. of Accounting Information Systems, Eastern Washington University

668 N. Riverpoint Blvd., Spokane, WA 99202-1677, USA

Tel: 1-509-828-1250Ｅ-mail: adjatej@ewu.edu

Received: April 1, 2012 Accepted: July 23, 2012 Published: December 1, 2012

doi:10.5296/ajfa.v4i2.1579ＵRL: http://dx.doi.org/10.5296/ajfa.v4i2.1579

\begin{abstract}
From the DuPont Identity, this paper derives a formula relating the percent changes in the return on equity (ROE) to the percent changes in the DuPont components. This formula is useful in determining the primary reasons why the ROE changed from one period to the next. While the periodic percent change relationship is nonlinear, a simple and intuitive additive formula is an approximation, albeit at times a poor approximation. We also convert the periodic percent changes in the ROE and its DuPont components into their equivalent instantaneous rates of change. These instantaneous rates of changes in the DuPont components do precisely sum to the instantaneous rate of change in the ROE, providing a method for analysts to both intuitively and accurately present their analysis.
\end{abstract}

Keywords: DuPont Identity, Time-series analysis, Return on equity 


\section{Introduction}

The DuPont Identity is a widely cited and extensively used relationship between the return on equity (ROE), the profit margin (PM), the total asset turnover rate (TAT), and the equity multiplier (EM). Sometimes analysts use the DuPont Identity to compare and interpret differences in these ratios among different firms (i.e., cross-sectional analysis). Analysts also at times use the DuPont Identity to analyze and interpret the changes of these ratios for a particular firm over time (i.e., time-series analysis). The existing literature on the DuPont Identity includes various extensions to the DuPont Identity that enhance the information revealed for cross-sectional analysis. However, we found no literature that improves the DuPont Identity's use for time-series analysis. To help facilitate the "time-series" type of comparisons, we extend the DuPont Identity to a relationship which relates the rate of change in the ROE to the rate of change in each of its components. The new relationship should be more useful than the DuPont Identity itself to explain why the ROE changes from one time period to the next.

This paper presents both the theoretical relationship and a simple additive approximation between the percent changes in the DuPont Identity components and the percent change in the ROE. Many analysts and their audiences will find the simplicity of the additive approximation more intuitive than the exact theoretical relationship. However, at times the impreciseness of the approximation can lead to incorrect results. To enable analysts to maintain precision while using the intuitively-appealing simple sum, we convert the periodic percent changes of the DuPont components to equivalent instantaneous percent changes. The sum of these instantaneous percent changes in the components does exactly equal the instantaneous percent change in the ROE. While some may find the formulas for the instantaneous percent changes daunting, we present them in a computer spreadsheet which enables analysts to quickly and easily make the conversions.

The next section presents a short literature review of the DuPont Identity. Section 3 then presents and explains our extension to the DuPont Identity. While this extension has a simple and intuitive additive approximation, that approximation can at time be misleading. Section 4 shows how we can convert the periodical rates of change to equivalent instantaneous rates of change where these instantaneous rates do exactly sum to instantaneous the rate of change in the ROE.

\section{Literature Review}

Instead of "DuPont Identity," the literature sometimes uses the labels "DuPont Equation," "DuPont Analysis," or "DuPont Model." Several articles in the literature use the definition of DuPont Identity in their analysis. For example, Van Voorhis et al. (1981) discuss how the DuPont Identity can be useful to small businesses. Mishra et al. (2008) apply the DuPont Identity to the agricultural economy in the U.S. Solliman (2007) empirically finds the information contained in the DuPont Identity's components is useful in determining the value of firms; he also finds that changes in the DuPont component ratios do have effects on investors' valuation of the firm. Dehning and Stratopoulos (2002) empirically use the DuPont component ratios to study information-technology firms to determine their comparative 
advantages in terms of profitability and efficiency.

Blumenthal (1998) discusses the advantages and disadvantages of the DuPont Identity compared to other methods of analysis. Other researchers utilize the DuPont Identity to supplement other methods of analysis. For example, Feroz et al. (2003) do "data envelopment analysis" based on the DuPont Identity by converting the DuPont component ratios to technical-efficiency equivalents. Feroz et al. then empirically demonstrate that the data envelopment analysis does add informational value relative to just using the DuPont ratios by themselves.

Other analysts have extended the DuPont Identity in various ways. These extensions break the DuPont components down into subcomponents. Bruns et al. (2008) extend the DuPont Identity to include the spreads between the return on net assets and the cost of debt to try to better deal with the effect of financial leverage. Colin (1997) discusses how the profit margin can be further broken down into three subcomponents: (i) an operating profit margin, (ii) an interest factor, and (ii) a tax factor. Callahan et al. (2007) is the most comprehensive discussion of the DuPont Identity and many of its extensions.

While there have been several additions to the DuPont Identity for cross-sectional analysis, none of these extensions have improved the use of the DuPont Identity for time-series analysis. Our paper fills this gap by providing what we refer to as a "growth-rate extension to the DuPont Identity."

\section{Growth-Rate Extension to DuPont Identity}

The DuPont Identity as presented in Parrino et al. (2012) is as follows where the $t$ subscript represents the period for each variable:

$$
R O E_{t}=P M_{t} T A T_{t} E M_{t}
$$

Where $R O E \equiv \frac{\text { net income }}{\text { sales }}, P M \equiv \frac{\text { net income }}{\text { sales }}, T A T \equiv \frac{\text { sales }}{\text { assets }}$, and $E M \equiv \frac{\text { assets }}{\text { equiity }}$.

The equity multiplier (EM) also equals one plus the debt-to-equity ratio.

To convert the DuPont Identity to a relationship involving changes of these variables, define $e, p, a$, and $m$ to be the growth rates in the ROE, PM, TAT, and EM respectively. Therefore, the following equations relate each variable at time $t$ to its value at time $t-1$ :

$$
\begin{gathered}
R O E_{t}=(1+e) R O E_{t-1} \\
P M_{t}=(1+p) P M_{t-1} \\
T_{A} T_{t}=(1+a) T_{t-1} \\
E M_{t}=(1+m) E M_{t-1}
\end{gathered}
$$

Equations (2), (3), (4), and (5) are standard application of growth rates where $x_{t}=(1+g) x_{t-1}$ where $g$ is the growth rate of a generic variable $x$. Also, note that this form is the same as for compound interest because the interest rate is the growth rate of the accumulated value on an account paying compound interest. 
If we substitute (2), (3), (4), and (5) into the DuPont Identity (1), we get:

$$
(1+e) R O E_{t-1}=(1+p) P M_{t-1}(1+a) T A T_{t-1}(1+m) E M_{t-1}
$$

By the associative law of multiplication, we can rearrange the terms to read:

$$
(1+e) R O E_{t-1}=(1+p)(1+a)(1+m) P M_{t-1} T_{A T} T_{t-1} E M_{t-1}
$$

Since the DuPont Identity (1) applied to time $t-1$ states that $R O E_{t-1}=P M_{t-1} T A T_{t-1} E M_{t-1}$., the term $R O E_{t-1}$ exists on both sides of the equation. By dividing both sides by $R O E_{t-1}$, we simply the above equation to the following:

$$
(1+e)=(1+p)(1+a)(1+m)
$$

We call equation (6) the "growth rate version of the DuPont Identity."

A linear approximation to (6) that may be more intuitive for many is:

$$
e \cong p+a+m
$$

While (7) may be more intuitive for some, (6) is the exact relationship; (7) is not exact. ${ }^{1}$

Table 1. DuPont Identity Example 1

\begin{tabular}{|c|c|c|c|c|}
\hline time & $\begin{array}{c}\text { Profit } \\
\text { Margin }\end{array}$ & $\begin{array}{c}\text { Total Asset } \\
\text { Turnover }\end{array}$ & $\begin{array}{c}\text { Equity } \\
\text { Multiplier }\end{array}$ & ROE \\
\hline 2008 & $5.00 \%$ & 1.2 & 2.2 & $13.20 \%$ \\
\hline 2009 & $5.50 \%$ & 0.8 & 2.2 & $9.68 \%$ \\
\hline $\begin{array}{c}\text { periodic \% } \\
\text { increase }\end{array}$ & $+10.00 \%$ & $-33.33 \%$ & $0.00 \%$ & $-26.67 \%$ \\
\hline $\begin{array}{c}\text { instantaneous } \\
\% \text { increase }\end{array}$ & $+9.53 \%$ & $-40.55 \%$ & $0.00 \%$ & $-31.02 \%$ \\
\hline
\end{tabular}

For an example to apply (6) and (7), assume the ratios presented in Table 1 . In this case between 2008 and 2009, the PM increased, but the TAT decreased, while the EM stayed the same. Since an increase in the $P M$ causes $R O E$ to increase and a decrease in the TAT causes the $R O E$ to decrease, we have opposite pressures on the $R O E$ to change. Equations (6) and (7) help explain why the $R O E$ decreased in this case. While the $P M$ increased by $10 \%$, the TAT decreased by over $30 \%$, which dominated the $P M$ effect.

For the reader's information, we computed the growth rates in PM, TAT, EM, and ROE as

${ }^{1}$ Equation (7) does hold with equality for instantaneous growth rates. However, if we apply (7) to periodic growth rates, then (7) only approximately holds. Later in this paper, we show how one can convert the periodic growth rates to equivalent instantaneous growth rates where (7) holds exactly. 
follows:

$$
\begin{gathered}
p \equiv \frac{P M_{t}-P M_{t-1}}{P M_{t-1}}=\frac{5.50 \%-5.00 \%}{5.00 \%}=10.00 \% \\
a \equiv \frac{T A T_{t}-T A T_{t-1}}{T A T_{t-1}}=\frac{0.8-1.2}{1.2}=-33.33 \% \\
m \equiv \frac{E M_{t}-E M_{t-1}}{E M_{t-1}}=\frac{2.2-2.2}{2.2}=0.00 \% \\
e \equiv \frac{R O E_{t}-R O E_{t-1}}{R O E_{t-1}}=\frac{9.68 \%-13.20 \%}{13.20 \%}=-26.67 \%
\end{gathered}
$$

It is important to note that the above formulas are implied by equations (2), (3), (4), and (5). Computing the percent increase in this manner is consistent with the concept of growth rate whereas other definitions of percent increase are not consistent with the concept of a growth rate. $^{2}$

Table 2. DuPont Identity Example 2

\begin{tabular}{|c|c|c|c|c|}
\hline time & $\begin{array}{c}\text { Profit } \\
\text { Margin }\end{array}$ & Total Asset Turnover & $\begin{array}{c}\text { Equity } \\
\text { Multiplier }\end{array}$ & ROE \\
\hline 2008 & $5.00 \%$ & 0.90 & 1.2 & $5.40 \%$ \\
\hline 2009 & $4.50 \%$ & 1.08 & 1.3 & $6.32 \%$ \\
\hline$\%$ increase & $-10.00 \%$ & $+20.00 \%$ & $+8.33 \%$ & $+17.00 \%$ \\
\hline $\begin{array}{c}\text { instantaneous } \\
\% \text { increase }\end{array}$ & $-10.54 \%$ & $+18.23 \%$ & $+8.00 \%$ & $+15.70 \%$ \\
\hline
\end{tabular}

If we apply the approximation (7), we would conclude that the $R O E$ decreased by approximately $23.33 \%$ (=10\%-33.33\%). However, if we apply (6), we get:

$(1+10.00 \%) \cdot(1-33.33 \%) \cdot(1+0 \%)=1.10 \cdot 0.6667 \cdot 1=0.7333=(1-26.67 \%)$

${ }^{2}$ For a generic variable $x$, a couple of other definitions of \% increases are $\frac{x_{t}-x_{t-1}}{x_{t}}$ and $\frac{x_{t}-x_{t-1}}{\left(x_{t}+x_{t-1}\right) / 2}$. (See Financial Times - Lexiton, 2012). These are often used in computing returns. However, neither of these gives the true growth rate. Hence, we argue that the true \% increase is given by $\frac{x_{t}-x_{t-1}}{x_{t-1}}$. 
which is consistent with the actual decrease in ROE by $26.67 \%$.

Table 2 presents a second example where all three components change, but in different directions. In this case, the approximation formula (7) indicates that the ROE should increase by $18.33 \%(=-10.00 \%+20.00 \%+8.33 \%)$, whereas the precise increase in $R O E$ is $17.00 \%$. To explain why the $R O E$ rose despite a $10 \%$ decrease in the profit margin, we note that the combined effect of the $20 \%$ and $8.33 \%$ respective increases in the TAT and the EM was greater than the $10 \%$ decrease in the profit margin.

Table 3. DuPont Identity Example 3

\begin{tabular}{|c|c|c|c|c|}
\hline time & $\begin{array}{c}\text { Profit } \\
\text { Margin }\end{array}$ & $\begin{array}{c}\text { Total Asset } \\
\text { Turnover }\end{array}$ & $\begin{array}{c}\text { Equity } \\
\text { Multiplier }\end{array}$ & ROE \\
\hline 2008 & $5.00 \%$ & 0.90 & 1.3 & $5.85 \%$ \\
\hline 2009 & $4.85 \%$ & 1.00 & 1.2 & $5.82 \%$ \\
\hline \% increase & $-3.00 \%$ & $+11.11 \%$ & $-7.69 \%$ & $-0.51 \%$ \\
\hline $\begin{array}{c}\text { instantaneous } \\
\% \text { increase }\end{array}$ & $-3.05 \%$ & $+10.54 \%$ & $-8.00 \%$ & $-0.51 \%$ \\
\hline
\end{tabular}

Next, consider the example in Table 3. In this example, equation (7) results with a positive $0.42 \%$ approximate increase in $R O E$, even though the ROE actually decreased by $0.51 \%$. While formula (6) precisely leads to the $0.51 \%$ ROE, many would find a simple sum such as (7) to be more intuitive. In a later section, this paper provides a description of how to convert the periodical percent increases to equivalent instantaneous percent increases, so that (7) holds with equality. Table 3 presents those instantaneous percentage increases for example 3 . When we add those instantaneous percentage increases, $-3.04 \%+10.53 \%-8.00 \%$, we get the exact $-0.51 \%$ change in the $R O E$.

Table 4. DuPont Identity Example 4

\begin{tabular}{|c|c|c|c|c|}
\hline time & $\begin{array}{c}\text { Profit } \\
\text { Margin }\end{array}$ & $\begin{array}{c}\text { Total Asset } \\
\text { Turnover }\end{array}$ & $\begin{array}{c}\text { Equity } \\
\text { Multiplier }\end{array}$ & ROE \\
\hline 2008 & $10.00 \%$ & 1.28 & 1.2 & $15.36 \%$ \\
\hline 2009 & 9.00 & 1.30 & 1.4 & $16.38 \%$ \\
\hline \% increase & $-10.00 \%$ & $+1.56 \%$ & $+16.67 \%$ & $+6.64 \%$ \\
\hline $\begin{array}{c}\text { instantaneous } \\
\text { \% increase }\end{array}$ & $-10.54 \%$ & $+1.55 \%$ & $+15.42 \%$ & $+6.43 \%$ \\
\hline
\end{tabular}

Table 4 presents an example where the growth rate formula (6) or its approximation (7) is more useful than the DuPont Identity itself for determining the real reason behind a $R O E$ increase. In this example, the ROE increased by 6.64\% between 2008 and 2009. Under normal circumstances, we usually would consider an increase in the ROE to be a good result. 
In this case, however, the $P M$ decreased by $10 \%$, the TAT increased by $1.56 \%$, and the Equity Multiplier (EM) increased by $16.67 \%$. We then conclude that the reason the $R O E$ increased was primarily related to the increase of the equity multiplier iby $16.67 \%$. Had the $P M$ decreased by $10 \%$ and TAT increased by $1.56 \%$, with no change in the equity multiplier, then the $R O E$ would have decreased by an approximate $8.44 \%$ according to (7) or an exact $8.59 \%$ according to (6). The sharp increase in the equity multiplier is an indicator of increased leverage, an increase in the use of debt to fund the company. While increased debt does usually increase expected return, increased debt also increases risk (Ross et al., 2006, pp. 538-40). ${ }^{3}$ One should not consider an increase in $R O E$ due to the increase in the Equity Multiplier $(E M)$ to be a good thing. A sharp analyst should note that the only positive development, a $1.56 \%$ increase in TAT is quite small compared to the $10 \%$ decrease in the $P M$. As a result, despite the $R O E$ increasing, a good analyst would conclude that the fundamentals of the components indicate that the firm is doing worse in 2009 than it did in 2008.

\section{Converting Periodic Rates of Change to Instantaneous Rates of Change}

Many analysts and especially their respective audiences will find the approximation formula (7) to be more intuitive than the exact relationship (6). For example, Bremster (1995, p. 8) states that forensic accountants and forensic economists need "to present testimony in an understandable fashion for the jury." " However, Bremster continues, the "opposing attorney's goal is to diminish the jury's confidence in the expert's opinion.” As Spizman and Weinstein (2008) warn, the opposing attorney could diminish a forensic accountant's or forensic economist's testimony that used an approximation rather than the precise relationship by stating, “'I wonder what other little overestimating errors you have made?'” The ideal would be to present one's results in a manner that is both understandable and precise.

This section explains why (7) is only an approximation for periodic rates of change. We then find that (7) actually holds with equality when we deal with equivalent instantaneous rates of change instead of periodic rates of change. We then develop the equations for a computerized spreadsheet that analysts can use to convert periodic rates of change to their equivalent instantaneous rates of change.

Note that the extension (6) to the Dupont Identity applies to any equation where one variable equals other variables multiplied together. Consider a simpler situation where $Z=X Y$ where $X$, $Y$, and $\mathrm{Z}$ are three generic variables. Then

$$
(1+z)=(1+x)(1+y)
$$

where $z, x$, and $y$ are the annual percentage increases in variables $Z, X$, and $Y$, respectively. Consider the specific situation where $x=+30 \%$ and $y=-30 \%$. Then $(1+z)=(1+30 \%)(1-30 \%)$, which equals .91 , which means that $z=-9.1 \%$ or $Z$ declines by $9.1 \%$. Clearly, this

\footnotetext{
3 The widely-held view that increased leverage increases expected return does not take into account the real options. On the hand, according to Guthrie (2011), the relationship may no longer be monotonic when the real option of abandoning projects is taken into account.

${ }^{4}$ As Waldrup et al. (2004, p. 1) note, the need for forensic accountants is more acute after the Enron and other accounting scandals.
} 
exemplifies that $z$ is not the sum of $30 \%$ and $-30 \%$. In particular, the $30 \%$ decrease had a larger impact than did the $30 \%$ increase.

We can use instantaneous rates of changes as a way to show the differences of the impacts between the $30 \%$ increase and the $30 \%$ decrease. Let $\tilde{x}$ be the instantaneous rate of change that is equivalent to the periodic rate of change $\mathrm{x}$. By equivalent, we mean that the effect over one period is the same, i.e., $(1+x)=\exp (\tilde{x})$, where $\exp ($.$) is the exponential function. { }^{5}$

Taking the natural logarithms of both sides gives:

$$
\tilde{x}=\ln (1+x)
$$

Equation (9) is how we convert a periodic rate of change to its equivalent instantaneous rate of change.

Applying (9) to the $30 \%$ increase gives $\tilde{x}=\ln (1+30 \%)=\ln (1.3)=+26.24 \%$. However,

applying (9) to the $30 \%$ decrease gives $\tilde{x}=\ln (1-30 \%)=\ln (0.7)=-35.67 \%$. This demonstrates that the instantaneous rate of decline of the $30 \%$ drop is greater in absolute value than the instantaneous rate of increase corresponding to the $30 \%$ increase. This confirms our earlier statement that the $30 \%$ drop has a greater impact than the $30 \%$ increase.

It turns out that converting the periodic rates of change to instantaneous rates of change will result in (7) holding precisely for the instantaneous rates of change. We do this conversion below by first repeating (6) and then replacing $(1+\mathrm{e})$ with $\exp (\tilde{e}),(1+\mathrm{p})$ with $\exp (\tilde{p}),(1+\mathrm{g})$ with $\exp (\tilde{g})$ and $(1+m)$ with $\exp (\tilde{m})$ :

$$
\begin{aligned}
& (1+e)=(1+p)(1+a)(1+m) \\
& \exp (\tilde{e})=\exp (\tilde{p}) \exp (\tilde{g}) \exp (\tilde{m})
\end{aligned}
$$

which can be simplified to:

$$
\exp (\tilde{e})=\exp (\tilde{p}+\tilde{g}+\tilde{m})
$$

Taking the natural logarithm of both sides of (10) gives:

$$
\tilde{e}=\tilde{p}+\tilde{g}+\tilde{m}
$$

\footnotetext{
${ }^{5}$ It is well known that with an instantaneous interest rate $\tilde{r}$, the principal and interest at the end of a period equals the beginning principal times the factor $\exp (\tilde{r})$. Similarly, with an instantaneous growth rate $\tilde{x}$, the value of the variable at the end of the period equals the beginning value times the factor $\exp (\tilde{x})$.
} 
Note that (11) is the same as (7) except that (11) holds with equality and (11) concerns the equivalent instantaneous rates of change rather than the periodic rates of change. In summary, by converting the periodic rates of change to their equivalent instantaneous rates, we then meet our objective of being able to discuss the relationship of these rates as a sum rather than using the less intuitive equation (6). Furthermore, for those who find the conversion to equivalent instantaneous rates of change to be complicated, Table 5 provides the formulas for a computerized spreadsheet that can easily make those conversions for the analyst.

For examples using the equivalent instantaneous rates of change, see Tables 1, 2, 3, and 4. In particular, for example 4, the instantaneous rates of change for the PM, TAT, and EM are $-10.54 \%,+1.55 \%$, and $+15.42 \%$. The sum of these equal $6.43 \%$, which equals the equivalent instantaneous rate of change for ROE.

\section{Conclusion}

Previous academic inquiries has extended the DuPont Identity to reveal more information for cross-sectional analysis. This paper leads the effort to extend the DuPont Identity to better serve those who use the Identity for time-series analysis. Our research presents a growth rate extension to the DuPont Identity that enables one to determine precisely why the $R O E$ changes as it does by looking at the percentage increases or decreases in the PM, TAT, and EM.

While we only extended the conventional presentation of the DuPont Identity to percent changes in its components, our extension methodology could also be applied to some more complex versions of the DuPont Identity that are described in the previous literature as long as the components are multiplied together. We encourage other researchers to pursue such applications of our methodology in future research.

This paper presents an approximation formula (7) that will be more intuitive to many in the analyst's audience than the precise equation (6) we derive. However, the imprecision of (7) could lead to some incorrect conclusions in some circumstances. Also, in the case of expert testimony in front of a jury or a judge, forensic accountants and forensic economists need to present their analysis in a relatively intuitive approach, but also need to maintain precision to

Table 5. Spreadsheet Formulas For Conversion to Equivalent Instantaneous \% Increases

\begin{tabular}{|c|c|c|c|c|c|}
\hline & B & C & D & $\mathrm{E}$ & $\mathrm{F}$ \\
\hline 2 & year & ROE & PM & TAT & EM \\
\hline 3 & 2008 & $=\mathrm{D} 3 * \mathrm{E} 3 * \mathrm{~F} 3$ & 0.1 & 1.28 & 1.2 \\
\hline 4 & 2009 & $=\mathrm{D} 4 * \mathrm{E} 4 * \mathrm{~F} 4$ & 0.09 & 1.3 & 1.4 \\
\hline 5 & gross \% increase & $=\mathrm{C} 4 / \mathrm{C} 3$ & $=\mathrm{D} 4 / \mathrm{D} 3$ & $=\mathrm{E} 4 / \mathrm{E} 3$ & $=F 4 / F 3$ \\
\hline 6 & net \% increase & $=C 5-1$ & $=\mathrm{D} 5-1$ & $=\mathrm{E} 5-1$ & $=\mathrm{F} 5-1$ \\
\hline 7 & $\begin{array}{l}\text { instantaneous \% } \\
\text { increase }\end{array}$ & $=\exp (\mathrm{C} 5)$ & $=\exp (\mathrm{D} 5)$ & $=\exp (\mathrm{E} 5)$ & $=\exp (\mathrm{F} 5)$ \\
\hline
\end{tabular}

avoid being discredited by the opposing attorney. To meet both needs, we show how an 
analyst can convert the periodic percent changes to their equivalent instantaneous percent changes so that these equivalent instantaneous percent changes do precisely add up to the instantaneous percent change in the return on equity.

\section{References}

Blumenthal, R. G. (1998). Tis the gift to be simple. CFO Magazine (January issue), Retrieved from http://www.cfo.com/article.cfm/2990236.

Bremster, W. (1995). Forensic Accounting and Fraud. American Management Association, Retrieved from http://www.flexstudy.com/catalog/schpdf.cfm?coursenum=95063

Burns; D. C., Sale, T. J., \& Stephan, J.A. (2008). A better way to gauge profitability: systematic ratio analysis using the advanced DuPont model. Journal of Accountancy, 206(\#2), 38-42.

Callahan, K. R., Stetz, G. S., \& Brooks, L. M. (2007). Project Management Accounting: Budgeting, Tracking, and Reporting Costs and Profitability. Hoboken, New Jersey USA: John Wiley \& Sons.

Colin, F. (1997). Investment basics: XXXIV. The Du Pont Identity. Investment Analysts Journal, 44, 71-73.

Dehning, B., \& Stratopoulos, T. (2002). DuPont analysis of an IT-enabled competitive advantage. International Journal of Accounting Information Systems, 3, 165-176. http://dx.doi.org/10.1016/S1467-0895(02)00032-5

Feroz, E. H., Kim, S., \& Raab, R. L. (2003). Financial statement analysis: A data envelopment analysis approach. Journal of Operational Research Society, 54, 48-58m. http://dx.doi.org/10.1057/palgrave.jors.2601475

Financial Times - Lexiton. (2012). Return on equity ROE. Retrieved March 20, 2012, from http://lexicon.ft.com/Term?term=return-on-equity--ROE

Firer, C. (1997). The Du Pont Identity. Investment Analysts Journal, 44, 71-73.

Guthrie, G. (2011). A note on operating leverage and expected rates of return. Finance Research Letters, 8(2), 88-100. http://dx.doi.org/10.1016/j.frl.2010.10.004

Mishra, A. K., Harris, J. M., Erickson, K., \& Hallahan, C. (2008). What drives agricultural profitability in the U.S.: application of the DuPont expansion method. paper presented at the American Agricultural Economics Association Annual Meeting, Orlando, FL, July 27-29, 2008, retrieved March 15, 2012, from http://ageconsearch.umn.edu/bitstream/6413/2/sp08mi30.pdf

Parrino, R., Kidwell, D., \& Bates T. (2012). Fundamentals of Corporate Finance (2 ${ }^{\text {nd }}$ ed.). Hobenken, NJ USA: John Wiley \& Sons

Ross, S., Westerfield, R. W., \& Jordan, B. D. (2006). Fundamentals of Corporate Finance ( $7^{\text {th }}$ ed.). New York, NY USA:McGraw-Hill/Irwin 


\section{Macrothink}

Asian Journal of Finance \& Accounting

ISSN 1946-052X 2012, Vol. 4, No. 2

Soliman, M. T. (2007). The use of DuPont Analysis by market participants. Retrieved from http://ssrn.com/abstract=1101981.

Spizman, L., \& Weinstein, M.A. (2008). A note on utilizing the geometric mean: when, why and how the forensic economist should employ the geometric mean. Journal of Legal Economics, 15(1), 43-55.

Van Voorhis, K. R. (1981). The DuPont model revisited: a simplified application to small business. Journal of Small Business Management, 19(2), 45-51.

Waldrup, B., Capriotti, K., \& Anderson, S.C. (2004). Forensic accounting techniques: a defensible investigatory process for litigation purposes. Journal of Forensic Accounting, 5, 1-16.

\section{Copyright Disclaimer}

Copyright reserved by the authors.

This article is an open-access article distributed under the terms and conditions of the Creative Commons Attribution license (http://creativecommons.org/licenses/by/3.0/). 